Original Research Article

\title{
Changing trends of antibiotic resistance in neonatal sepsis in a tertiary care hospital
}

\author{
Pauline Packiaseeli S.*, Ashok Kumar T.
}

Department of Pharmacology, Kanyakumari Government Medical College, Nagercoil, Tamilnadu, India

Received: 08 April 2017 Accepted: 28 April 2017

*Correspondence to:

Dr. Pauline Packiaseeli S., Email: paulinepackiaseeli.s@ gmail.com

Copyright: (C) the author(s), publisher and licensee Medip Academy. This is an openaccess article distributed under the terms of the Creative Commons Attribution NonCommercial License, which permits unrestricted noncommercial use, distribution, and reproduction in any medium, provided the original work is properly cited.

\begin{abstract}
Background: Sepsis and other infections cause 15\% neonatal deaths in India. The present study is to determine the resistance pattern of pathogens causing neonatal sepsis and to provide antibiogram to pediatricians for better patient management.

Methods: Positive Blood culture reports of neonatal sepsis cases detected during the years 2014 and 2015 were studied. The antibiotic resistance of the organisms found during the years 2014 and 2015 were compared by calculating the probability ( $\mathrm{p}$ value) using the standard formula.

Results: Coagulase negative staphylococci (CONS) was the most common organism in 2014 whereas pseudomonas was predominant in 2015.Resistance of CONS to amoxycillin and ceftrioxone has significantly increased in 2015.Also resistance of CONS to vancomycin was noted. Resistance of Pseudomonas to cefuroxime, ceftazidime and amoxicillin/clavulanuic acid combination were increased but not significantly. There was also emerging resistance of pseudomonas to gentamicin and amikacin. Resistance of acinetobacter to cefuroxime, ceftrioxone and gentamicin has increased in 2015 but not significantly. Citrobacter showed a significant increase in resistance to amoxicillin/clavulanic acid combination $(\mathrm{p}=0.006)$.

Conclusions: Bacterial spectrum causing neonatal sepsis varies in different regions, varies in the same site during different time periods, also their antibiotic resistance pattern varies in different regions and changes constantly. Increase in resistance to commonly used antibiotics stress the need of rational use of antibiotics.
\end{abstract}

Keywords: Antibiotic resistance, Neonatal sepsis, Retrospective study, Tertiary care hospital

\section{INTRODUCTION}

Neonatal sepsis or sepsis neonatorum is a clinical syndrome resulting from systemic infection and bacterimia in the first month of life. ${ }^{1}$ Sepsis and other infections cause $15 \%$ neonatal deaths in India. ${ }^{2}$ Indiscriminate use of broad spectrum antibiotics without appropriate blood cultures and the practice of not stopping their use when no infection is documented has resulted in high antibiotic resistance rate among organisms isolated in India. ${ }^{3}$ The present study is to determine the resistance pattern of pathogens causing neonatal sepsis and to provide antibiogram to Pediatricians for better patient management.

\section{METHODS}

This is a retrospective study of antibiotic resistance patterns in positive Blood culture reports of neonatal sepsis cases detected during the years $2014\left(1^{\text {st }}\right.$ January to $30^{\text {th }}$ December $)$ and 2015 ( $1^{\text {st }}$ January to $30^{\text {th }}$ December $)$. After obtaining the approval from the ethical committee, the blood culture reports of neonatal sepsis cases were obtained from the Department of microbiology and screened. The incidence and antibiotic resistance of both the Gram positive and Gram negative microorganisms 
were found by calculating their percentages. The antibiotic resistance of the commonly occurring organisms during the years 2014 and 2015 was compared by calculating the probability ( $p$ value) using the standard formula. The ' $p$ ' value less than 0.05 was defined significant.

\section{RESULTS}

In the year 2014, the most common Gram positive organism was CONS (43\%) followed by staphylococcus aureus $(11 \%)$, enterococci $(5 \%)$ and streptococci $1 \%$. In the year 2015, the most common Gram positive organism was again CONS (12\%) followed by enterococci $(6 \%)$, staphylococcus aureus (5\%), and streptococci $2 \%$.

Table 1: percentages of Gram positive microorganisms present in the blood cultures collected during the year 2014 and 2015 (from $1^{\text {st }}$ January to $31^{\text {st }}$ December).

\begin{tabular}{|lll|}
\hline Name of the organism & Year 2014 & Year 2015 \\
\hline CONS & $43 \%$ & $12 \%$ \\
\hline Staphylococcus aureus & $11 \%$ & $4 \%$ \\
\hline Enterococci & $5 \%$ & $6 \%$ \\
\hline Streptococci & $1 \%$ & $2 \%$ \\
\hline
\end{tabular}

In the year 2014 Klebsiella spp. (33\%) was the most common Gram negative organism followed by Acinetbacter spp. (19\%), Pseudomonas spp. (14\%). Citrobacter spp. (11\%), Proteus mirabilis (4\%) and Escherchia coli (1\%). In 2015, Pseudomonas spp. (29\%) was the predominant organism followed by Klebsiella spp (26\%), Acinetbacter spp (12\%), Citrobacter spp. (7\%), and Escherchia coli $(2 \%)$.

The resistance of CONS to amoxicillin and ceftrioxone has significantly increased in 2015. Also, CONS showed $10 \%$ resistance to vancomycin in 2015.The sensitivity of staphylococcus aureus to amoxicillin did not show any change in both the periods but the resistance to ceftrioxone was raised to $33 \%$ in 2015 .

Table 2: The percentages of Gram negative microorganisms present in the blood cultures collected during the year 2014 and 2015 (from $1^{\text {st }}$ January to $31^{\text {st }}$ December).

\begin{tabular}{|lll|}
\hline Name of the organism & Year 2014 & Year 2015 \\
\hline Acinetobacter & $19 \%$ & $12 \%$ \\
\hline Klebsiella & $33 \%$ & $26 \%$ \\
\hline Pseudomonas & $14 \%$ & $29 \%$ \\
\hline Citrobacter & $11 \%$ & $7 \%$ \\
\hline Proteus & $4 \%$ & 0 \\
\hline Escherichia coli & $1 \%$ & $2 \%$ \\
\hline
\end{tabular}

Klebsiella spp. showed a significant increase in resistance to cefuroxime in 2015.The resistance of Klebsiella spp. to amikacin, ceftrioxone/ sulbactam combination and ciprofloxacin was also increased but not significantly.

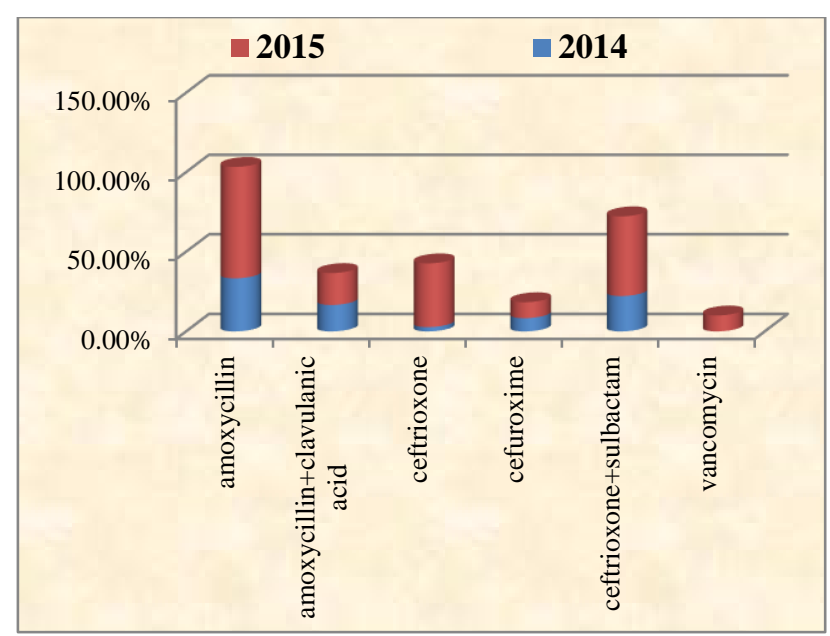

Figure 1: Comparison of antibiotic resistance pattern in Coagulase negative Staphylococcus aureus in 2014 and 2015.

The resistance of Acinetobacter to cefuroxime, ceftrioxone, ceftazidime and gentamicin has increased in 2015 but not significantly.

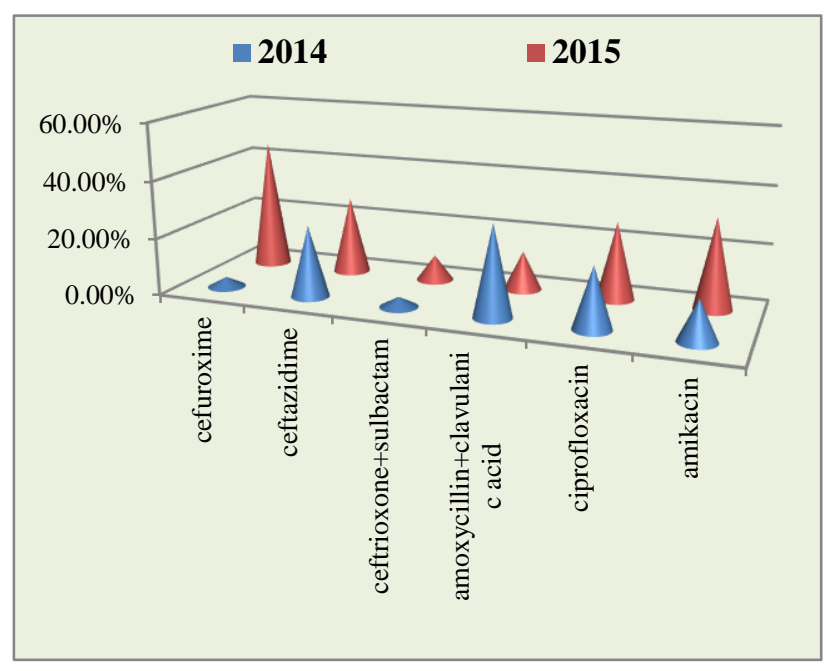

Figure 2: Comparison of antibiotic resistance pattern in Klebsiella spp. in 2014 and 2015.

Regarding Pseudomonas spp. there was emerging resistance to gentamicin, amikacin whereas the resistance to cefuroxime, ceftazidime and amoxicillin/ clavulanic acid combination was increased in 2015 but not significantly.

Citrobacter spp. showed a significant increase in resistance to amoxicillin/clavulanic acid combination $(p=0.006)$. It also showed an increase in resistance to amikacin, cefuroxime, ciprofloxacin, ceftrioxone/ sulbactam combination and other $3^{\text {rd }}$ and $4^{\text {th }}$ generation cephalosporins. 


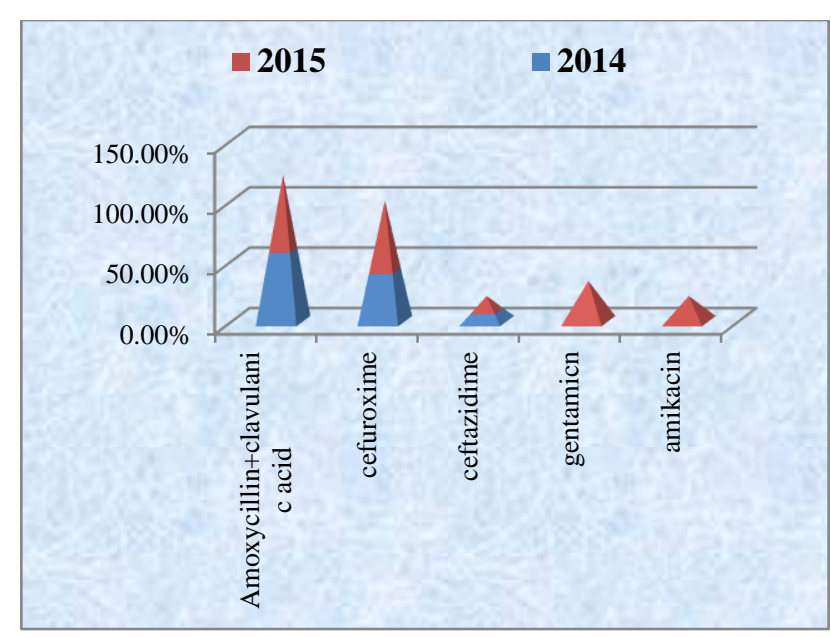

Figure 3: Comparison of antibiotic resistance pattern in Pseudomonas spp. in 2014 and 2015.

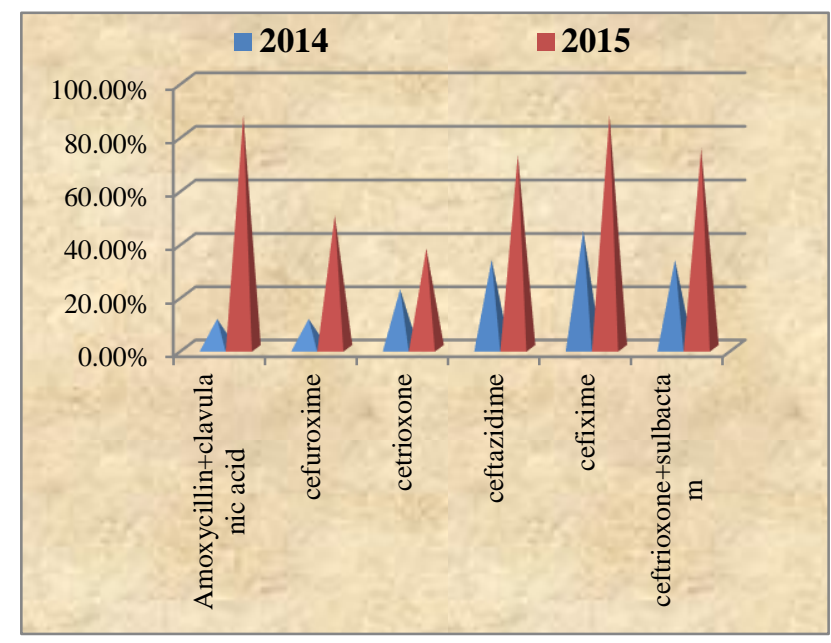

Figure 4: Comparison of antibiotic resistance pattern in Citrobacter spp. in 2014 and 2015.

\section{DISCUSSION}

In this study, the positive blood culture reports of neonatal septicemia cases detected during the years 2014 ( $1^{\text {st }}$ January to $30^{\text {th }}$ December) and 2015 ( $1^{\text {st }}$ January to $30^{\text {th }}$ December) obtained from the Department of microbiology were studied.

In the year 2014 CONS (43\%) was the most common organism followed by Klebsiella spp. (33\%) and Acinetobacter spp. (19\%).This result was similar to that in the study by Arpita et al where CONS (27\%) was the most common organism and also in the Delhi neonatal study CONS (46\%) was the commonest organism in one of the sites. ${ }^{4,5}$ Whereas in other studies by Sharma CM et al and Marwah P et al Staphylococcus aureus was the commonest. ${ }^{6,7}$ In the year 2015 , the status was completely different with Pseudomonas spp. (29\%) as the commonest followed by Klebsiella spp. (20\%), Acinetobacter spp. (12\%) and CONS (12\%).whereas in other studies by Viswanathan et al and Al Taiar et al
Klebsiella spp. was the commonest. ${ }^{8,9}$ In the Delhi neonatal study Acinetobacter spp. (27\%) and Klebsiella (25\%) were shown to be predominant in two different sites. ${ }^{5}$ This shows that Pseudomonas spp. has emerged as the most common organism causing neonatal sepsis. This inference shows that there is a high preponderance of hospital acquired infection. Hospital acquired infection can be minimized by good hand hygiene, promoting provision of Breast milk to sick LBW neonates, good adherence to asepsis protocols and strict antibiotic policy that limits its use when required. ${ }^{3}$

Then comparing the antibiotic resistance of the common organisms in the year 2014 and 2015, CONS showed significant increase in resistance to amoxicillin $(\mathrm{p}=0.042)$ and to ceftriaxone $(\mathrm{p}=0.0016)$. So, this increase in resistance to the first line antibiotic and also the thirdgeneration cephalosporin may be due to injudicious use of antibiotics when not needed, which could be avoided in future. Increase in resistance to amoxicillin/clavulanic acid combination and cefuroxime was not much significant. But, in the study by Arpita et $\mathrm{al}^{4}$ Gram positive organisms showed more resistance to amoxicillin/clavulanic acid combination (55\%). ${ }^{4}$ It was alarming to notice that $10 \%$ of CONS showed resistance to vancomycin in 2015 , but it was $100 \%$ sensitive to vancomycin in another study by Madhur Sharma et al. ${ }^{6}$ Staphylococcus aureus showed no resistance to ceftrioxone in 2014 but it has increased to $33 \%$ in 2015 . So, judicious use of vancomycin is also a need of the hour.

Klebsiella spp showed significant increase in resistance to cefuroxime $(\mathrm{p}=0.0009)$ in 2015. It showed no significant increase in resistance to amikacin, ceftrioxone/sulbactam combination and ciprofloxacin. Resistance to cephalosporins may be related to the inability of the antibiotic to reach its site of action due to alteration in the penicillin binding proteins (PBPs) that are the targets of the cephalosporins such that the antibiotics bind to bacterial enzymes ( $\beta$-Lactamases) that can hydrolyze the $\beta$-lactam ring and inactivate the cephalosporins. ${ }^{10}$ Third generation cephalosporins are susceptible to hydrolysis by inducible chromosomally encoded type $1 \beta$ lactamases. ${ }^{10}$

Regarding Pseudomonas spp. there was emerging resistance to gentamicin (33\%), amikacin (20\%), whereas in a study by Sharma CM et al the sensitivity of Pseudomonas spp. to amikacin was $100 \% .^{6}$ Clinically drug inactivation is the most common mechanism for any microbial resistance. The genes encoding aminoglycoside-modifying enzymes are acquired primarily by conjugation and transfer of rsistance plasmids. ${ }^{10}$ The resistance Pseudomonas to amoxicillin/clavulanic acid combination (62\%), cefuroxime $(58 \%)$, ceftazidime $(12 \%)$ was increaseed in 2015 but not significantly. The resistance is mediated by plasmid encoded enzymes (e.g. $\beta$-lactamases and acetylating enzymes). ${ }^{11} \quad$ Neonates infected with 
pseudomonas spp. had the highest case fatality rate. ${ }^{5}$ So, the increasing burden of resistant Pseudomonas spp. might pose a formidable threat in the coming years.

Acinetobacter spp. did not show any increase in resistance to amoxicillin/ clavulanic acid combination in 2015. This report is in sharp contrast to that in Delhi neonatal study. ${ }^{5}$ where Acinetobacter spp. showed $82 \%$ multidrug resistance and $38 \%$ resistance to extended spectrum penicillins. Citrobacter spp. showed a significant increase in resistance to amoxicillin/clavulanic acid combination $(p=0.006)$. This may be due to the fact that there is a frequent use of amoxicillin/clavulanic acid combination in our area. Citrobacter spp. occurs in the environment and in the human colon and can cause sepsis in immunocompromised patients. ${ }^{11}$ It also showed an increase in resistance to amikacin, cefuroxime, ciprofloxacin, ceftrioxone/sulbactam combination and other $3^{\text {rd }}$ and $4^{\text {th }}$ generation cephalosporins. The emergence of antibiotic resistance in pathogens that infect the newborns is of great concern. Antibiotics interfere with colonization of normal flora, thereby facilitating colonizaton with more virulent pathogens. The rational use of antibiotics in neonates involves using narrow-spectrum drugs when possible, treating infections and not colonization and limiting the duration of therapy. ${ }^{12}$

\section{CONCLUSION}

Bacterial spectrum causing neonatal sepsis varies in different regions. It may also vary in the same site during different time periods. Antibiotic resistance also varies and in fact it is increased mostly in 2015 when compared to 2014 in the same site. Surveillance of pathogens and their resistance patterns should be done in regular intervals so that it can help in empirical treatment of neonatal sepsis.

Funding: No funding sources

Conflict of interest: None declared

Ethical approval: The study was approved by the Institutional Ethics Committee

\section{REFERENCES}

1. Bhat SR. Achar's textbook of Pediatrics. $4^{\text {th }} \mathrm{Ed}$, University Press, Chapter 11, neonatology. 2099:215.

2. Neonatal and child health Profile, Department of maternal, newborn, child and adolescent health
(MCA/WHO) Source: chreg/WHO, UNICEF) from Distribution of cases of neonatal and under 5 deaths (publlshed in Lancet 2014).

3. Parthasarathy A, Gupta P, Agarwal R, Menon PSN, Nair MKC, Sukumaran TV. IAP Textbook of Pediatrics. $5^{\text {th }}$ Ed. JayPee Brothers; 2013:46.

4. Shah AJ, Mulla SA, Revdiwala SB. Neonatal sepsis: high antibiotic resistance of the bacterial pathogens in a neonatal intensive care unit of a tertiary care hospita. J Clin Neonatol. 2012;1(2):72-5.

5. Investigators of Delhi Neonatal study (DeNIS) collobaration. Characterisation and antimicrobial sensitivity of sepsis pathogens in neonates born in tertiary care centers in Delhi, India: a cohort study. The Lancet Global health. 2016;4(10):e752-e760.

6. Sharma CM, Agrawal RP, Sharan H, Kumar B, Sharma D, Bhatia SS. Neonatal Sepsis: Bacteria and their Susceptibility Pattern towards Antibiotics in Neonatal Intensive Care Unit. J Clin Diagn Res. 2013 Nov;7(11):2511-3.

7. Marwah P, Chawla D, Chander J, Guglani V, Marwah A. Bacteriological profile of neonatal sepsis in a tertiary-care hospital of Northern India. Indian Pediatr. 2015;52(2):158-9.

8. Viswanathan R, Singh AK, Mukherjee S, Mukherjee R, Das P, Basu S. Aetiology and antimicrobial resistance of neonatal sepsis at a tertiary care centre in eastern India: a 3 year study. Indian J Pediatr. 2011Apr;78(4):409-12.

9. Al-Taiar-A, Hammoud MS, Cuiquing I, Lee JK, Lui KM, Nakwan N, Isaac D. Neonatal infections in China, Malaysia, Hong Kong and Thailand. Arch Dis Child Fetal Neonatal Ed. 2013May;98(3):F249-55.

10. Brunton LL, Chabner BA, Knollman BC. Goodman and Gilman's Pharmacological basis of Therapeutics. $12^{\text {th }}$ edition. 2011:1493,1496,1508.

11. Levinson W. Review of Medical Microbiology and Immunology, $13^{\text {th }}$ ed. McGraw Hill education; 2014:214.

12. Stanton K, Behrman STGS. Nelson's Text Book of Pediatrics. 19 $19^{\text {th }}$ Ed, Elseviers (Saunders) Chapter 103.5, page 635, Chapter103.8, page 644 .

Cite this article as: Packiaseeli PS, Kumar AT. Changing trends of antibiotic resistance in neonatal sepsis in a tertiary care hospital. Int J Basic Clin Pharmacol 2017;6:1344-7. 